\title{
Auricular Seroma: Our Technique
}

\author{
${ }^{1}$ Priyadarshini Govindarajalu, ${ }^{2}$ Ayisha Kunnumal
}

\begin{abstract}
Introduction: Pseudocyst or seroma is an uncommon asymptomatic, non-inflammatory swelling of the pinna, characterized by endochondral cyst formation. Various treatments are available such as needle aspiration, curettage following incision and drainage and subsequent contour pressure dressing, deroofing procedure or insertion of a small drainage tube into the pseudocyst with a guide needle. The purpose of this study was to develop a new technique for the treatment of auricular seroma.

Materials and methods: In this study 43 patients with seroma of auricle who presented to ENT OPD of AVMC and were treated during the period between August 2015 to August 2018 were included. All cases of seroma auricle were managed with the technique of primary drainage and suturing. Consent was obtained explaining the possibility of change in shape. Sutures were removed on the 10th day. All patients were called for follow-up at 1 month.
\end{abstract}

Results: In our study male to female ratio was $2: 1$. The common age group was found to be $20-40$ years with a total of 28 patients. Sixty-three percent presented with seroma in the right auricle and $37 \%$ of patients presented with left ear seroma. Majority of the patients, that is, $75 \%$ had no known cause for developing the seroma. Seroma completely disappeared without disfigurement in all patients.

Conclusion: Auricular seroma was noted to completely disappear without disfigurement with incision and drainage of fluid with pressure suturing. Our technique is an office procedure and can be carried out under local anesthesia with promising results.

Keywords: Auricular seroma, Pinna, Suturing

How to cite this article: Govindarajalu $P$, Kunnumal $A$. Auricular Seroma: Our Technique. Int J Otorhinolaryngol Clin 2018;10(3):91-93.

Source of support: Nil

Conflict of interest: None

\section{INTRODUCTION}

Pseudocyst or seroma is an uncommon asymptomatic, non-inflammatory swelling of the pinna, characterized by endochondral cyst formation. ${ }^{1}$ Repeated minor trauma has long been suspected to have some part in

\footnotetext{
${ }^{1}$ Assistant Professor, ${ }^{2}$ Junior Resident

${ }^{1}$ Department of ENT, Aarupadai Veedu Medical College, Puducherry, India

${ }^{2}$ Department of Otolaryngology, Aarupadai Veedu Medical College, Puducherry, India

Corresponding Author: Priyadarshini Govindarajalu, Assistant Professor, Department of ENT, Aarupadai Veedu Medical College, Puducherry, India, e-mail: priyababu2512@gmail.com
}

the pathogenesis of auricular pseudocyst. This includes sleeping on hard pillows, carrying large weights on the shoulder. ${ }^{2}$ As the etiology is obscure, various treatments are followed such as needle aspiration, curettage following incision and drainage and subsequent contour pressure dressing, deroofing procedure or insertion of a small drainage tube into the pseudocyst with a guide needle. ${ }^{2}$

The purpose of this study was to develop a new technique for the treatment of auricular seroma.

\section{MATERIALS AND METHODS}

In this study, 43 patients with seroma of auricle who presented to ENT OPD of AVMC and were treated during the period between August 2015 to August 2018 were included.

All cases of seroma auricle were managed with the technique of primary drainage and suturing. Consent was obtained explaining the possibility of change in shape. Under all aseptic precautions, the seroma was drained by giving an incision on the summit of it. All fluid was drained and the cavity was washed with betadine. Through and through sutures were taken using 5-0 prolene (Fig. 1). Betadine dressing was done and the patient was put on the adequate antibiotic cover and followed up on the 3rd day and 10th day. Sutures were removed on the 10th day (Fig. 2). All patients were called for follow-up at 1 month.

\section{RESULTS}

Out of the 43 patients, 29 were males $(67 \%)$ and $14(33 \%)$ were females. Male-to-female ratio was 2:1 (Graph 1).

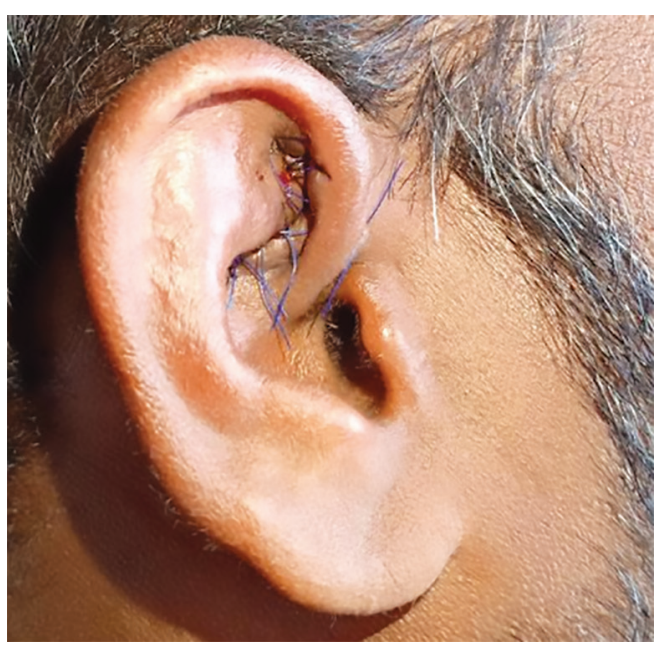

Fig. 1: Sutures in situ 


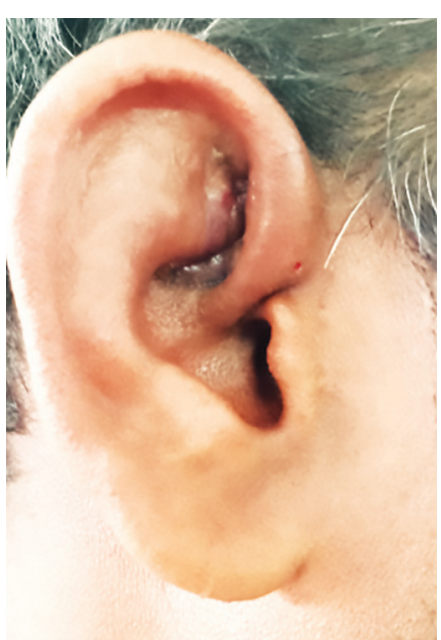

Fig. 2: 10th day postoperation

The most common age group was found to be 20-40 years with a total of 28 patients $(65 \%)$. The least common was $10-20$ years with 2 patients (4\%) and 13 patients $(30 \%)$ in the age group of 40-50 years. The youngest patient was 17 years, and the oldest was 49 years (Table 1 ).

\section{Laterality of Seroma}

Twenty-seven patients (63\%) presented with seroma in the right auricle and 16 patients (37\%) presented with left ear seroma. None of the patients had a bilateral auricular seroma (Graph 2).

\section{Etiology of Seroma}

Out of 43 patients majority, that is, 32 patients (75\%) had no known cause for developing the seroma. Seven

Table 1: Age distribution

\begin{tabular}{lll}
\hline Age & No. of patients & Percentage \\
\hline $10-20$ & 2 & 4 \\
$20-30$ & 14 & 33 \\
$30-40$ & 14 & 33 \\
$40-50$ & 13 & 30 \\
$50-60$ & 0 & 0 \\
\hline
\end{tabular}

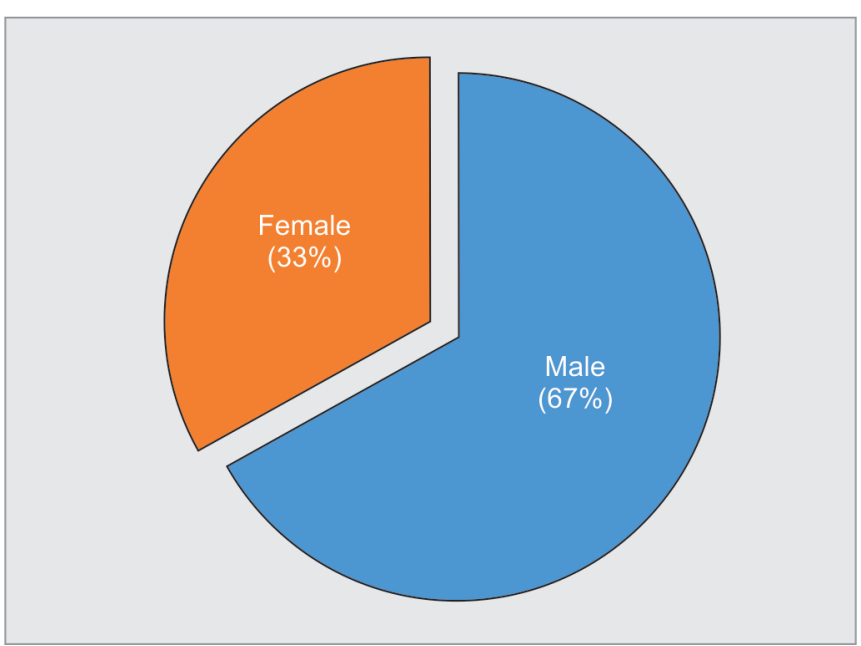

Graph 1: Gender distribution patients $(16 \%)$ gave a history of blunt trauma to the ear, and 4 patients (9\%) gave a history of other trauma for example slap over the ear (Table 2).

\section{Complications}

Of the 43 patients, 10 patients had previously undergone aspiration, but they presented with recollection. Mild deformation of the pinna was noted in 9 out of 10 patients who had undergone prior aspiration.

All patients were reviewed on the 3rd day and 7th day. Sutures were removed on the 10th day.

None of the patients developed recollection, swelling, fever or pain. In all patients seroma completely disappeared without disfigurement.

\section{DISCUSSION}

In our study commonest age group presenting with seroma was found to be 20-40 years with a total of 28 patients. In a study by Bhat et al. ${ }^{3}$ majority of the patients were in the age group between 41 years and 50 years. Malgonde et al. ${ }^{4}$ reported a mean age of 23.9 years. Juboori et al. ${ }^{5}$ reported mean age with a standard deviation of 29 years \pm 2.4 years.

In our study, $67 \%$ were males $33 \%$ were females. Male to female ratio was $2: 1$. In a similar study by Bhat et al. ${ }^{3}$ they reported 18 males and 12 females. Hansen et al. ${ }^{6}$ in their studies on seromas found them only in males. In a study by Malgonde et al., ${ }^{4} 18$ patients were males, and 2

Table 2: Etiology of seroma

\begin{tabular}{lll}
\hline Etiology & No. of patients & Percentage \\
\hline Blunt trauma & 7 & 16 \\
Other trauma e.g. slap over ear & 4 & 9 \\
Minor repeated trauma & 0 & 0 \\
Sleeping on hard pillow & 0 & 0 \\
Carrying large weight on shoulders & 0 & 0 \\
None of the above & 32 & 75
\end{tabular}

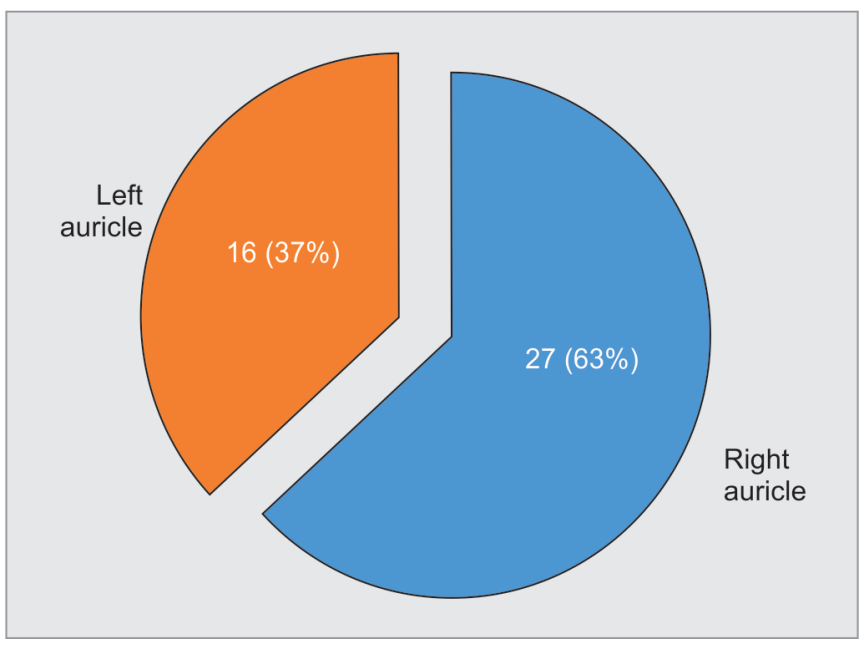

Graph 2: Laterality of seroma 
patients were females. Juboori et al. ${ }^{5} 84 \%$ were male, and $16 \%$ of patients were female.

In our study, $63 \%$ of patients presented with seroma in the right auricle and $37 \%$ of patients presented with left ear seroma. Malgonde et al. ${ }^{4}$ reported 13 patients with right ear seroma and 7 patients with left earseroma.

In our study, $75 \%$ patients had no known cause for developing the seroma. Sixteen of the patients gave a history of blunt trauma to the ear, and $9 \%$ of patients gave a history of other trauma. Kikura et al. ${ }^{7}$ analyzed 16 cases of auricular seroma and found that they occurred in patients without any history of trauma, insect bites, or bruising. Juboori et al. ${ }^{5}$ reported that personal insult on the pinna happened in $40 \%$ of patients. Sports injuries from football and boxing occurred in $28 \%$ of patients, while road traffic accidents and occupational hazards had been recorded.

\section{CONCLUSION}

Auricular seroma was noted to completely disappear without disfigurement with incision and drainage of fluid with pressure suturing. Our technique is an office procedure and can be carried out under local anesthesia with promising results.

\section{REFERENCES}

1. Prasad KC, Karthik S, Prasad SC. A comprehensive study on lesions of the pinna. Head and Neck Medicine and Surgery. Am J Otolaryngol. 2005;26:1e6.

2. Choi S, Lam KH, Chan KW, et al. Endochondralpseudocyst of the auricle in Chinese. Arch Otolaryngol. 1984;110: $792 \mathrm{e} 796$.

3. Mahesh Bhat $\mathrm{T}$, Rao VV, Rosario D. Cruciate incision for treatment of primary/recurrent cases of seroma/hematoma of pinna: A novel approach. J ClinDiagn Res 2015;9:MC01-2.

4. Malgonde MS, Kumar M. Auricular seroma:A new concept in management. PlastAesthet Res 2014;1:13-15.

5. Al-juboori AN .Treatment of Auricular Hematoma with Compression Using X-ray Films. Gen Med (Los Angel) 1: 101.

6. Hansen JE. Pseudocyst of the Auricle in Caucasians. Archives of Otolaryngology. 1967;85:35-36.

7. Kikura M, Hoshino T, Matsumoto M, et al. Auricular seroma: A new concept, and diagnosis and management of 16 cases. Arch Otolaryngol Head Neck Surg 2006; 132 (10): 1143-1147. 